\title{
Correction to: Mission to Planet Earth: The First Two Billion Years
}

\author{
E.E. Stüeken ${ }^{1,2} \cdot$ S.M. Som ${ }^{3}$ M. Claire ${ }^{1,2,3}$. \\ S. Rugheimer ${ }^{4}$ - M. Scherf ${ }^{5}$ - L. Sproß ${ }^{5,6} \cdot$ N. Tosi ${ }^{7,8}$. \\ Y. Ueno ${ }^{9,10}$ • H. Lammer ${ }^{5}$
}

Published online: 6 April 2020

(C) Springer Nature B.V. 2020

\section{Correction to: Space Sci Rev (2020) 216: 31 \\ https://doi.org/10.1007/s11214-020-00652-3}

Due to an unfortunate turn of events the wrong affiliation number was given for Dr. $\mathrm{H}$. Lammer. Please find on this page the correct affiliation number behind his name.

Publisher's Note Springer Nature remains neutral with regard to jurisdictional claims in published maps and institutional affiliations.

Reading Terrestrial Planet Evolution in Isotopes and Element Measurements Edited by Helmut Lammer, Bernard Marty, Aubrey L. Zerkle, Michel Blanc, Hugh O’Neill and Thorsten Kleine

The original article can be found online at https://doi.org/10.1007/s11214-020-00652-3

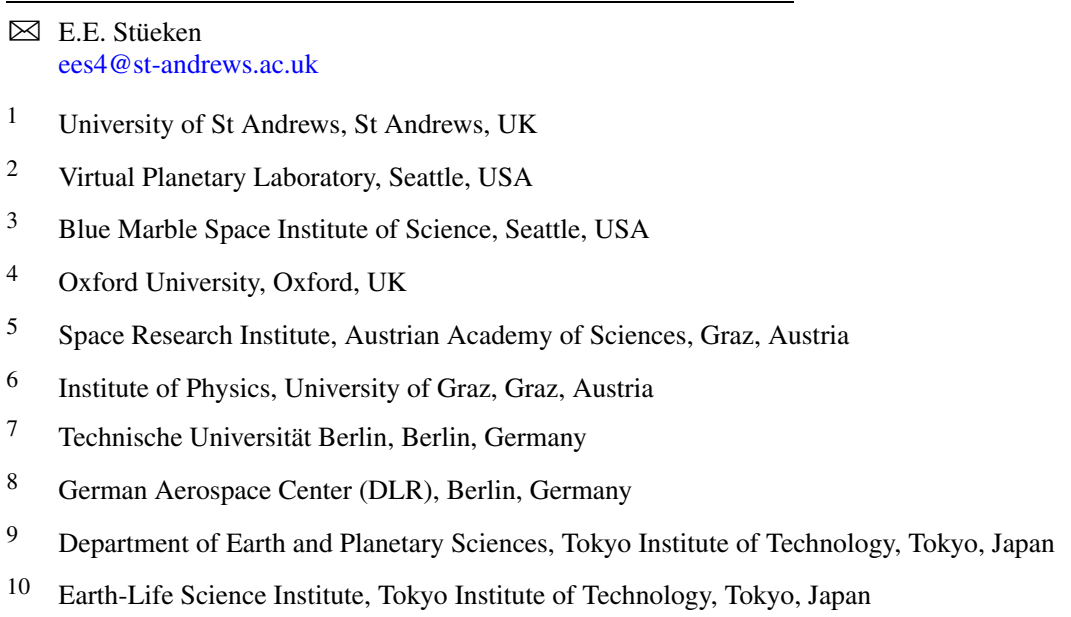

